\title{
Structures for Heat Treatment Assembled from Cast Elements
}

\author{
Bogdan Piekarski $^{\mathrm{a}}{ }_{\mathbb{C}}$, Andrzej Drotlew $^{\mathrm{b}}$ \\ ${ }^{a}$ West Pomeranian University of Technology Szczecin, Department of Materials Technology, al. Piastów 17, 70-310 Szczecin, Poland \\ bPrzedsiębiorstwo Usług Odlewniczych POLCAST Sp. J., al. Piastów 19, 70-310 Szczecin, Poland \\ *e-mail: bogdan.piekarski@zut.edu.pl
}

(C) 2020 Authors. This is an open access publication, which can be used, distributed and reproduced in any medium according to the Creative Commons CC-BY 4.0 License requiring that the original work has been properly cited.

Receive 28 May 20202/Accepted: 17 September 2020/ Published online: 4 November 2020

This article is published with open access at AGH University of Science and Technology Press

\begin{abstract}
Various types of technological equipment individually designed for operation in pit and elevator heat treatment furnaces are described in this article. A common characteristic of these structures is that they are composed of several or several dozen thin-walled elements of various shapes and sizes, gravity cast in sand moulds from creep-resistant alloys (austenitic $\mathrm{Cr}-\mathrm{Ni} / \mathrm{Ni}-\mathrm{Cr}$ cast steel and cast nickel alloys). The design of the castings requires the development of a manufacturing technology that can effectively use the principle of the simultaneous solidification of all components. Properly designed equipment should have minimum weight, maximum strength, and maximum loading capacity combined with adequate durability and reliability. Two designs of the equipment for the heat treatment of steel parts were presented. Both designs, as well as their individual components, were described in detail and illustrated. The main task of the equipment is to form the charge in the furnace and transport this charge both inside and outside the furnace. The first design is the design of an equipment for the heat treatment of large ring-shaped parts. The second design is the design of an equipment, whose structure can be modified using various repeatable components. As a result of these modifications, different variants of the equipment are obtained, allowing for the heat treatment of five different types of the shafts characterized by different shapes and sizes. The study is of an application nature. It is addressed to engineering and technical staff dealing with both the design and operation of heat treatment furnaces.
\end{abstract}

\section{Keywords:}

castings for heat treatment plants, design of castings, grates

\section{INTRODUCTION}

Heat treatment furnaces are widely used in all industries. One of the basic factors determining their efficiency and reliability is the quality of the technological equipment used to form the charge (the parts subjected to heat treatment) in the furnace working chamber. Another task of the equipment is to transport the charge both in the furnace chamber and in the space of the production hall. It should also be noted that the cost of making or purchasing this equipment contributes significantly to the overall operating cost of the furnace [1-4].

Typical technological equipment for heat treatment is a metal frame on which heat-treated parts are laid. It usually comprises the following main components $[4,5]$ :

- a grate, which is the base of the frame,

- spacers (other grates can also perform this function) serving as shelves,

- pillar(s) and sleeves, whose length determines the height of the equipment and the distance between the grate and spacers,

- other elements, e.g. hangers, allowing for proper arrangement of heat-treated parts on the frame.
The above mentioned components are primarily assembled by means of detachable connections. Such connections facilitate the exchange of elements when the type of charge is changed and replacement of worn out elements. A loose fit also allows them to undergo a relatively free thermal deformation in the field of their operating temperature [2].

In most cases, better durability and reliability of the equipment can be obtained, when it is made of cast parts and not of wrought semi-finished products. The elements are cast mainly from creep-resistant austenitic $\mathrm{Cr} / \mathrm{Ni}$ or $\mathrm{Ni} / \mathrm{Cr}$ cast steel. Occasionally, cast nickel alloys are also used [1-4].

The aim of this study is to present two non-standard designs of technological equipment for the heat treatment of some selected parts. Currently, this equipment is used in the industry, gaining positive opinions from users. The first design is intended for operation in a pit furnace, the second - for operation in an elevator furnace. Both designs are original designs developed by the authors of this study as part of completed projects, and as such are subject to intellectual property protection resulting, among others, from The Act of 4 February 1994 on Copyright and Related Rights, the Act of 30 June 2000 on Industrial Property Law and the Act of 16 April 1993 on Combating Unfair Competition. 


\section{HEAT TREATMENT EQUIPMENT}

Before the Contractor undertakes the heat treatment of the commissioned parts, he must decide whether he can use the already existing technological equipment, or whether the equipment has to be redesigned and custom-made. The choice of the second solution is more likely when the production is of a lot or mass character, or when the parts produced are not typical in respect of the shape, dimensions, weight, and/or properties required after the heat treatment process [1-4].

The equipment discussed in this article was designed for the heat treatment of steel parts, such as:

- rings (Fig. 1a),

- 5 types of shafts (Fig. 1b).

a)

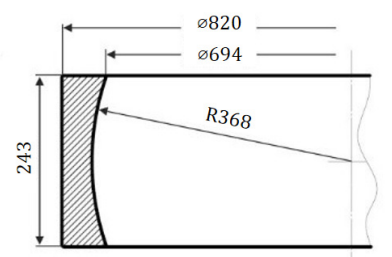

b)

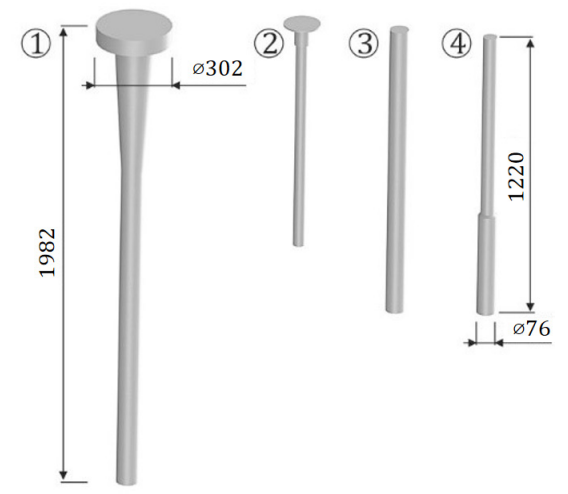

Fig. 1. Heat-treated steel parts: a) ring; b) shafts: 1, 2, 3, 4 - shaft types

\subsection{Equipment for the heat treatment of steel rings}

To carry out the heat treatment of rings (Fig. 1a), with each ring weighing $230 \mathrm{~kg}$, the technological equipment presented in Figure 2 was constructed in a pit furnace.

The equipment comprises 5 elements (Fig. 3a). Assembled together (Fig. 3), they form a frame on which the heat-treated parts are laid. Elements (Fig. 3a): 1 (pipe/central pillar), 2 (base) and 5 (transport hitch) are permanently connected by welding. Pipe ( 1 - Fig. 3a) can be made by casting, but a simpler and cheaper solution is to use a seamless steel pipe (e.g. made from 1.4841 steel) with a wall thickness of $8 \mathrm{~mm}$. Elements 3 and 4 do not require a permanent connection - they can be loosely put together. Element 3 is bevelled at corners (see Fig. 3a-b) to place the charge (ring 6 - see Fig. 3b) on the frame using a forklift (Fig. 4).

The designed equipment (Figs. 2 and 3) guarantees a stable position for the heat-treated parts, an adequate flow of atmosphere inside the furnace working chamber, and relatively easy loading and unloading of the charge.

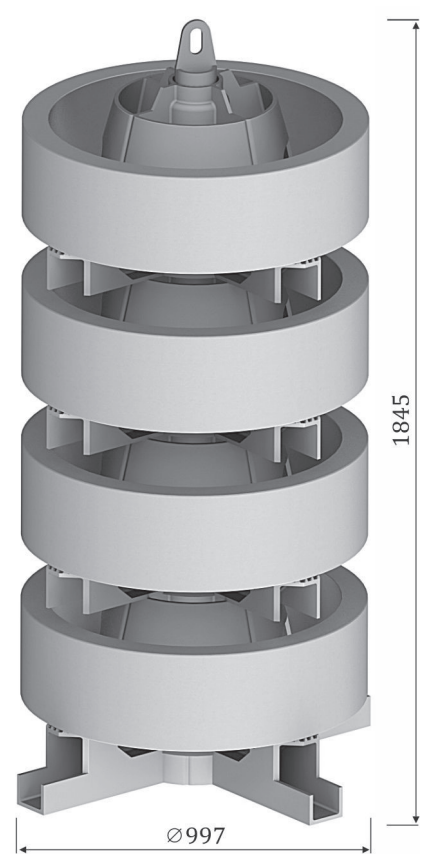

Fig. 2. Technological equipment for the heat treatment of rings (Fig. 1a) loaded with the charge a)

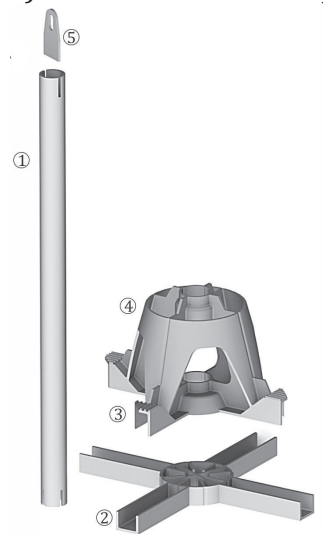

b)

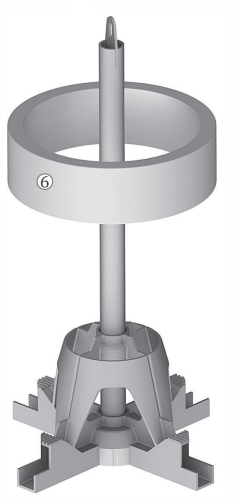

c)

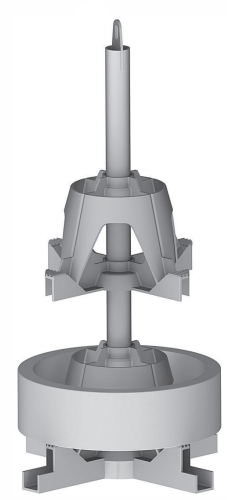

Fig. 3. Parts of the equipment shown in Figure 2 (a) and the method of its assembly and arrangement of the charge - heat-treated rings (b-c). Equipment elements: 1 - pipe/central pillar, 2 - base, 3 - support, 4 - positioning cone, 5 - transport hitch, 6 - heat-treated ring (Fig. 1a)

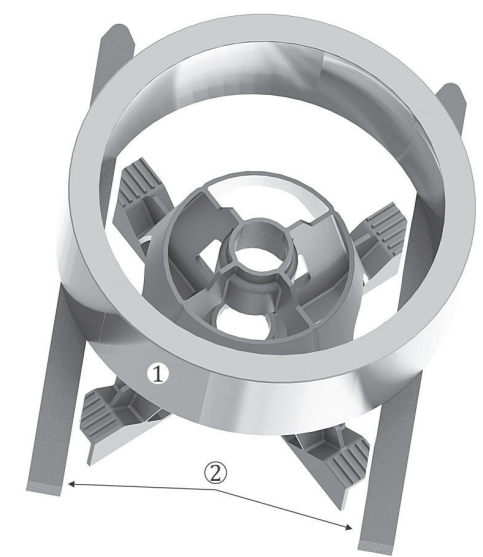

Fig. 4. Ring placed on the frame (Fig. 3) using a forklift: 1 - heat-treated ring, 2 - forklift forks 


\subsection{Modified equipment for the heat treatment of steel shafts}

The equipment designed for operation in the elevator furnace with a working chamber of $\emptyset 1000 \times 2100 \mathrm{~mm}$ should meet the following conditions:

- allow for the heat treatment of 5 types of shafts (Fig. 1b) each weighing from 20 to $70 \mathrm{~kg}$,

- have a maximum weight of $500 \mathrm{~kg}$ together with the charge.

Contrary to the equipment shown in Figure 2, this equipment is designed for operation without the use of a transport hitch.

The charge is placed in the furnace working chamber or pulled out of this chamber using a manipulator which simultaneously grips the equipment with jaws from the bottom and the top.

Three designs of the equipment (designated in further part of the text as I, II, III) were developed, and it was decided to use in each design as many common elements as possible. As a consequence of this decision, the components of the equipment can be divided into the following three groups:

1. Grates (Fig. 5) with the same external dimensions but modified internal design: A, B and C. The type of the heat-treated shaft determines the type of the grate used in the equipment (Fig. 1b). For casting each of the grates, pattern $\mathbf{A}$ and two types of overlays were used. Their proper imposition on the main pattern allowed the use of cores reproducing:

- $\quad$ sockets "U" with dimensions smaller in grates B and C than in grate $\mathbf{A}$,

- $\quad$ sockets with support ribs “D” in grate C (see Fig. 5C).

2. Components of the same shape and dimensions: pipe/ central pillar (1), supports (2) and pins (3) (see Fig. 6a - equipment I). They are also used in equipment II and III.

3. Other elements, such as flange (4 - Fig. 7a) and two plugs (5 - Fig. 7a); they are used to position grate $\mathbf{B}$ in equipment II (Fig. 7a) and middle grate $\mathbf{B}$ in equipment III (Fig. 8).

Equipment I (Fig. 6). Only shafts of one type are hung in this equipment (1 - Fig. 1b). The equipment consists of the following components (see Fig. 6a):

grates $(\mathbf{A}, \mathbf{B})-1$ piece of each, pipe/central pillar (1) - 1 piece,

supports (2) - 8 pieces,

pins (3) - 8 pieces.

Grates A and B. Their central holes have grooves for the positioning of the pillar (1 - Fig. 6) and holes for mounting supports (2) with pins (3).

Supports (2 - Fig. 6a) are used to stiffen the structure of the equipment (see Figs. 6b, 7b-c and 8), position the upper and lower grate and prevent pillar deformation by ensuring the more even distribution of mechanical loads resulting from the presence of the charge. The supports end with a dovetail (a) on one side to enable mounting them in the pillar, and with a yoke (b) on the other side for their assembly on the ribs of the lower and upper grate.

Pillar (1 - Fig. 6a) made from steel or cast steel has three types of slots made by milling:

- the largest slots for fixing supports ending on one side with a dovetail (a),

- smaller (middle) slots for mounting the flange (4) using two plugs (5) (see Fig. 7a). The flange with plugs is used only in equipment II and III.

- the smallest slots made at the pillar ends. They keep the pillar in position in the lower and upper grate - the pillar is inserted into the grooves made in the central hole of the grate.

Equipment II (Fig. 7) is used for the heat treatment of parts 3 and 4 (see Fig. 1b). Compared to equipment I (see Figs. 7 and 6), its new elements include flange (4) and two plugs (5) that position grate B. Two grates B and C (Fig. 7a) (see also Fig. $7 b-c$ ) are used in the construction of this equipment. The heat-treated shafts (see Fig. 7b-c) "pass" through the openings of grate $\mathbf{B}$, while in grate $\mathbf{C}$ they are resting in appropriately shaped sockets (see also Fig. 5c).

Equipment III (Fig. 8) is used for the heat treatment of shaft 2 (Fig. 1b). Shafts are hung on two levels - grates B.

In all grates where shafts are hung (equipment I, II and III), the " $U$ " sockets can be additionally milled to make them "deeper" and ensure in this way an equal support for the flanges of the shafts that are heat-treated in a hanging position.

A

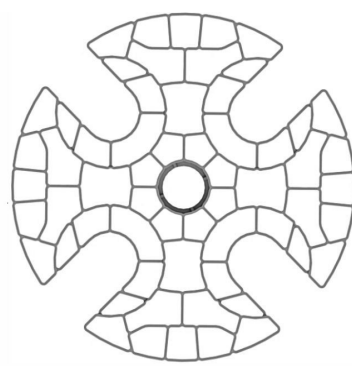

B

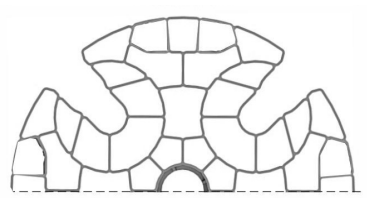

C

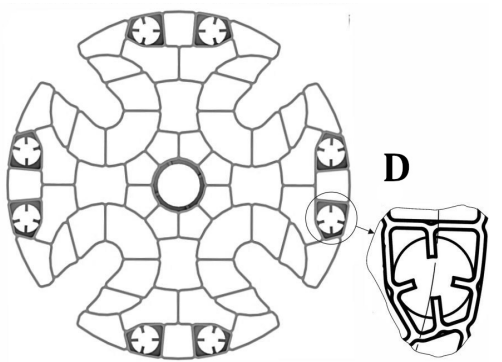

Fig. 5. Grates used in equipment for the heat treatment of shafts: A, B , C - grate types, D - socket with support ribs 
a)

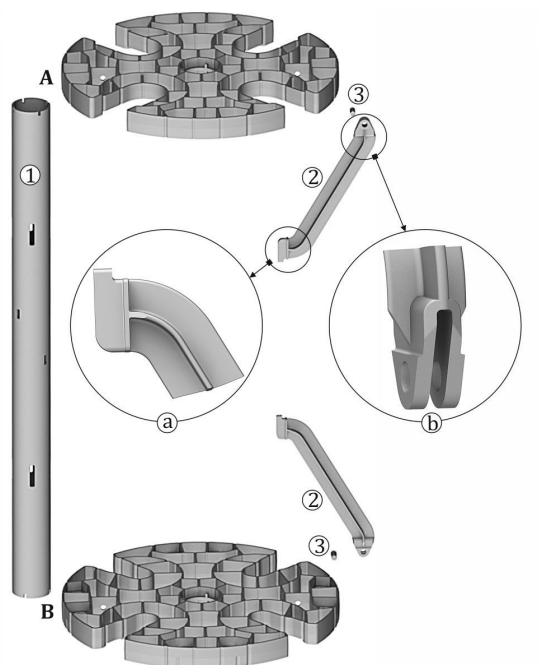

b)

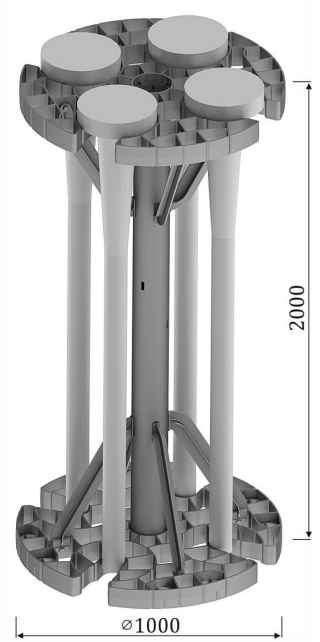

Fig. 6. Equipment I. Components of the equipment: A, B - grates, 1 - pipe/central pillar , 2 - support, 3 - pin (a) and equipment with hanging shafts (part 1; see Fig. 1b)

a)

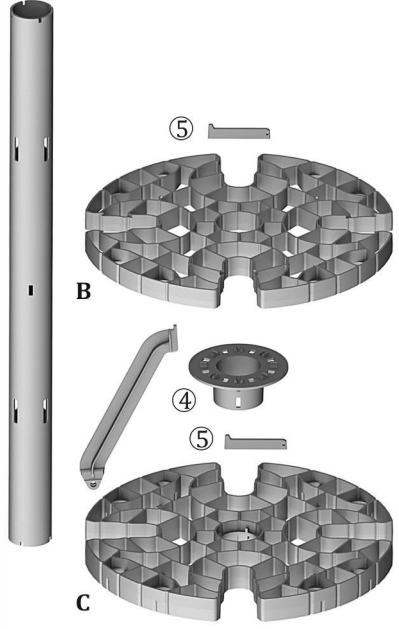

b)

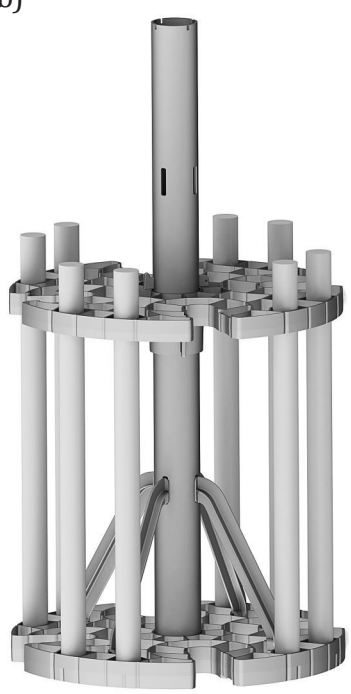

c)

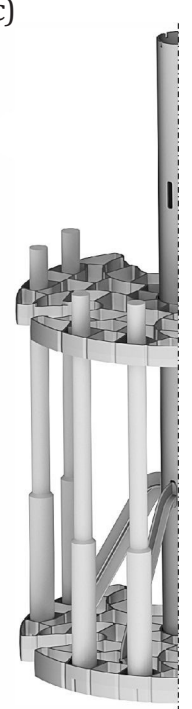

Fig. 7. Equipment II. Components of the equipment for the heat treatment of parts 3 and 4 (see Fig. 1b) (a) and positioning of these parts in the equipment: part 3 (b), part 4 (c); 4 - flange, 5 - plugs

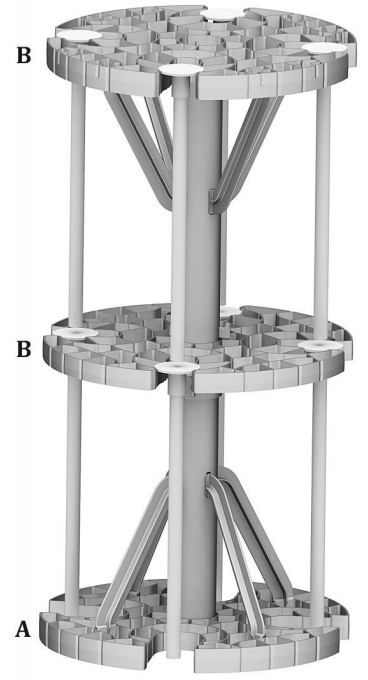

Fig. 8. Equipment III for the heat treatment of part 2 (see Fig. 1b) 


\section{FINAL REMARKS}

The design and manufacture of the technological equipment for heat treatment is generally considered to be the most labour-intensive and costly process in the entire preparation of this treatment. Additionally, the design of the equipment has a significant impact on the quality and efficiency of production. It can be assumed that the majority of technical problems which arise during heat treatment are caused by the improper design of the equipment.

Whether or not the technological equipment has been correctly designed and has the required quality mainly depends on the skill, experience, practice and knowledge of the designer, and also on their understanding of the thermal fatigue process which will affect the technological equipment during operation [6-9].

Necessary elements of the designer's knowledge and experience also include the following issues:

- design solutions that can ensure the maximum possible speed of assembly/disassembly of parts of the equipment,

- use of proven technologies for the manufacture and assembly/joining of parts of the equipment,

- use of available means of the mechanization of work, transport and machines to reduce to minimum the time necessary for the preparation of production and performance of heat treatment operations as well as the number of modifications and parts necessary in the equipment,

- knowledge of the available stock of assembled structures and of their versatility which, combined with new adaptation and modernization projects, can significantly facilitate and accelerate all work in the field of implementation of new equipment. In accordance with current trends in the design of this type of equipment, it can also have a modular structure allowing for significant cost reduction and gradual expansion.
Progress in this area of technology is extensively supported by the rapid and continuous development of various methods of designing the technological equipment, with an important contribution being made by IT methods and computer-aided techniques.

\section{REFERENCES}

[1] Steinkusch W. (1987). Hitzebeständiger Stahlguss für Wärmebehandlungsanlagen. Gas Wärme International, 6, 340-346.

[2] Drotlew A. \& Piekarski, B. (2020). Connecting castings for operation under conditions of cyclic temperature changes. Journal of Castings \& Materials Engineering, 4(1), 16-21.

[3] Davis J.R. (ed.) (1997). Industrial Applications of Heat-Resistant Materials. In: Heat Resistant Materials ASM International, 67-85.

[4] Piekarski B. (2012). Odlewy ze stopów żarowytrzymałych w piecach do obróbki cieplnej. Szczecin: Wydawnictwo Uczelniane Zachodniopomorskiego Uniwersytetu Technologicznego w Szczecinie.

[5] Folders: Lohmann, Cronite, Pose-Marre, Technoalloy, MANOIR PETRO-CHEM, AFE Technologies, NCK, Polcast.

[6] Piekło J. \& Pysz S. (2000). Kształtowanie wytrzymałościowe odlewu palety transportowej stosowanej w piecach tunelowych na podstawie analizy numerycznej pola temperatury i stanu naprężenia. Biuletyn Instytutu Odlewnictwa, 1(3), 3-13.

[7] Nandwana D., Bhupendra N.K., Khandelwal N., Bhargava T., Nandwana K. \& Jawale G. (2010). Design, finite element analysis and optimization of HRC trays used in heat treatment process. Proceedings of the World Congress on Engineering WCE 2010. II, 1149-1154.

[8] Bajwoluk A. \& Gutowski P. (2016). Thermal stresses in the wall connections of cast grate structures. Archives of Foundry Engineering, 4, 11-16.

[9] Bajwoluk A. \& Gutowski P. (2019). Stress and crack propagation in the surface layer of carburized stable austenitic alloys during cooling. Materials at High Temperatures, 36(1), 9-18. Doi: 10.1080/09603409.2018.1448528. 